\title{
Longitudinal changes in compliance, oxygenation and ventilatory ratio in COVID-19 versus non-COVID-19 pulmonary acute respiratory distress syndrome
}

François Beloncle ${ }^{1,2^{*}} \mathbb{D}$, Antoine Studer ${ }^{3}$, Valérie Seegers ${ }^{4}$, Jean-Christophe Richard ${ }^{1,5}$, Christophe Desprez ${ }^{1}$, Nicolas Fage ${ }^{1}$, Hamid Merdji, ${ }^{3,6}$, Bertrand Pavlovsky ${ }^{1}$, Julie Helms ${ }^{3,6}$, Sibylle Cunat ${ }^{3}$, Satar Mortaza ${ }^{1}$, Julien Demiselle $e^{1,3,6}$, Laurent Brochard ${ }^{7,8}$, Alain Mercat ${ }^{1}$ and Ferhat Meziani $i^{3,6}$

\begin{abstract}
Background: Differences in physiology of ARDS have been described between COVID-19 and non-COVID-19 patients. This study aimed to compare initial values and longitudinal changes in respiratory system compliance $\left(C_{R S}\right)$, oxygenation parameters and ventilatory ratio (VR) in patients with COVID-19 and non-COVID-19 pulmonary ARDS matched on oxygenation.
\end{abstract}

Methods: 135 patients with COVID-19 ARDS from two centers were included in a physiological study; 767 nonCOVID-19 ARDS from a clinical trial were used for the purpose of at least 1:2 matching. A propensity-matching was based on age, severity score, oxygenation, positive end-expiratory pressure (PEEP) and pulmonary cause of ARDS and allowed to include 112 COVID-19 and 198 non-COVID pulmonary ARDS.

Results: The two groups were similar on initial oxygenation. COVID-19 patients had a higher body mass index, higher $C_{\mathrm{RS}}$ at day 1 (median [IQR], 35 [28-44] vs 32 [26-38] $\mathrm{ml} \mathrm{cmH}_{2} \mathrm{O}^{-1}, p=0.037$ ). At day 1, $C_{\mathrm{RS}}$ was correlated with oxygenation only in non-COVID-19 patients; $61.6 \%$ and $68.2 \%$ of COVID-19 and non-COVID-19 pulmonary ARDS were still ventilated at day $7(p=0.241)$. Oxygenation became lower in COVID-19 than in non-COVID-19 patients at days 3 and 7, while $C_{\text {RS }}$ became similar. VR was lower at day 1 in COVID-19 than in non-COVID-19 patients but increased from day 1 to 7 only in COVID-19 patients. VR was higher at days 1, 3 and 7 in the COVID-19 patients ventilated using heat and moisture exchangers compared to heated humidifiers. After adjustment on $\mathrm{PaO}_{2} / \mathrm{FiO}_{2}, \mathrm{PEEP}$ and humidification device, $C_{R S}$ and VR were found not different between COVID-19 and non-COVID-19 patients at day 7. Day-28 mortality did not differ between COVID-19 and non-COVID-19 patients (25.9\% and 23.7\%, respectively, $p=0.666$ ).

Conclusions: For a similar initial oxygenation, COVID-19 ARDS initially differs from classical ARDS by a higher $C_{R S}$, dissociated from oxygenation. $C_{R S}$ become similar for patients remaining on mechanical ventilation during the first week of evolution, but oxygenation becomes lower in COVID-19 patients.

Trial registration: clinicaltrials.gov NCT04385004

*Correspondence: Francois.beloncle@univ-angers.fr

${ }^{1}$ Medical ICU, University Hospital of Angers, Vent'Lab, University of Angers, Angers, France

Full list of author information is available at the end of the article

(c) The Author(s) 2021. Open Access This article is licensed under a Creative Commons Attribution 4.0 International License, which permits use, sharing, adaptation, distribution and reproduction in any medium or format, as long as you give appropriate credit to the original author(s) and the source, provide a link to the Creative Commons licence, and indicate if changes were made. The images or other third party material in this article are included in the article's Creative Commons licence, unless indicated otherwise in a credit line to the material. If material is not included in the article's Creative Commons licence and your intended use is not permitted by statutory regulation or exceeds the permitted use, you will need to obtain permission directly from the copyright holder. To view a copy of this licence, visit http://creativecommons.org/licenses/by/4.0/. The Creative Commons Public Domain Dedication waiver (http://creativeco mmons.org/publicdomain/zero/1.0/) applies to the data made available in this article, unless otherwise stated in a credit line to the data. 
Keywords: Mechanical ventilation, Respiratory failure, Respiratory mechanics, Dead space, Acute Respiratory Distress Syndrome, Covid-19

\section{Introduction}

Most of the patients admitted to ICU for coronavirus disease 2019 (COVID-19) present severe respiratory failure fulfilling acute respiratory distress syndrome (ARDS) criteria according to the Berlin definition [13]. Several hypotheses emerged from the literature, but little is known about the specific pathophysiology of COVID-19-associated ARDS. Based on clinical observations reported in small series, it has been advocated that part of the patients with COVID-19 ARDS may be characterized by severe hypoxemia and relatively normal respiratory system compliance $\left(C_{\mathrm{RS}}\right)$ and may beneficiate from a "less protective" ventilation compared to the "classical form" of ARDS [4]. In addition, some data suggested that COVID-19-associated ARDS may be characterized by a high pulmonary dead space fraction [5]. The description of a high ventilatory ratio (VR) which has been shown to be associated with an increased dead space in some patients with COVID19-associated ARDS may also support this observation $[6,7]$. These data may be consistent with histologic analysis of lungs from patients who died from COVID19 showing distinctive vascular features with severe endothelial injuries and widespread thrombosis [8]. In addition, a high risk of thrombotic complications has been found in patients with COVID-19-associated ARDS [9-11]. Cumulating evidence coming from larger series tends to demonstrate that variability in clinical presentation (depending on ARDS severity) exists in COVID-19 as it has been described in non-COVID19-associated ARDS, thus challenging this interesting conceptual "new phenotype" specific to COVID-19-associated ARDS [12-16]. Based on this statement, these authors advocated that the well-described "lung protective strategy" should be adapted to a systematic daily physiological evaluation similarly in COVID-19 and non-COVID-19-associated ARDS patients [12, 14, 16, 17]. This controversy is of clinical importance since it may impact the ventilatory approaches proposed to manage COVID-19-associated ARDS patients [18]. Facing a clinical presentation that we considered atypical, we hypothesized that the first week time course evolution of $C_{\mathrm{RS}}$ and gas exchange may differentiate COVID-19 from non-COVID-19 forms of pulmonary ARDS. The aim of this study was to prospectively assess $C_{\mathrm{RS}}$, oxygenation parameters and VR from day 1 to day 7 in patients with COVID-19-associated ARDS and to compare them to patients with pulmonary
non-COVID-19-associated ARDS. For this purpose, patients admitted for COVID-19-associated ARDS were matched with patients with non-COVID-19 pulmonary ARDS included in a previously published large randomized controlled trial (Express Study [19]), using a propensity score matching.

\section{Methods}

\section{Patients' selection}

Patients with COVID-19-associated ARDS (COVID-19 cohort). Adult patients admitted from March 3 to April 27, 2020, to two French tertiary care teaching medical ICUs (University hospitals of Angers and Strasbourg, France) and intubated for COVID-19-associated ARDS, were prospectively included within $24 \mathrm{~h}$ after ARDS diagnosis for longitudinal physiology assessment. ARDS was defined according to the Berlin definition criteria [3]. SARS-Cov-2 infection was confirmed by real-time reverse transcriptase-polymerase chain reaction (RTPCR) assay of nasal swabs or lower respiratory tract samples (bronchoalveolar lavage or endotracheal aspirate). Exclusion criteria were age lower than 18 years and use of extracorporeal membrane oxygenation (ECMO) within $24 \mathrm{~h}$ after ARDS diagnosis. Some of these patients have been included in previously published studies $[9,17]$.

Patients with pulmonary non-COVID-19 ARDS (nonCOVID-19 cohort). Patients with non-COVID-19-associated ARDS came from the Express study, a large randomized control trial performed from September 2002 to December 2005, and were eligible as control patients [19]. In brief, patients with ARDS or acute lung injury using the American-European Consensus Conference on ARDS criteria [20] were enrolled in the study within $48 \mathrm{~h}$ after ARDS diagnosis. Patients were then randomly assigned to two different positive end-expiratory pressure (PEEP) titration strategies: PEEP was set to a level of 5 to $9 \mathrm{cmH}_{2} \mathrm{O}$ in the minimal distension strategy or to a level set to reach a plateau pressure of 28 to 30 $\mathrm{cmH}_{2} \mathrm{O}$ in the increased recruitment strategy.

\section{Ventilation and sedation strategies}

Both in the two centers and in the Express trial, recommendations for initial management included a deep sedation and the use of neuromuscular blockers for 24 to $48 \mathrm{~h}$. Patients were ventilated in volume-controlled mode with a tidal volume of $6 \mathrm{ml} \mathrm{kg}^{-1}$ of predicted body weight (PBW) and a respiratory rate up to $35 \mathrm{~min}^{-1}$, adjusted according to arterial $\mathrm{pH}$ (objective between 7.30 and 
7.45). The fraction of inspired oxygen $\left(\mathrm{FiO}_{2}\right)$ was set for an arterial oxygen saturation between 88 and $98 \%$.

In the COVID-19 cohort, PEEP setting was left to the discretion of attending physician according to gas exchange and hemodynamic tolerance with an upper limit of plateau pressure of $28 \mathrm{cmH}_{2} \mathrm{O}$, similar to Express.

All patients were switched to pressure-support ventilation when oxygenation improved and PEEP level was decreased to $5-8 \mathrm{cmH}_{2} \mathrm{O}$.

The COVID-19 patients were ventilated using a heated humidifier or a heat and moisture exchanger (HME, Humid-Vent Compact, Teleflex, Athlone, Ireland, dead space $=35 \mathrm{ml}$ or Clear Therm 3 Filter, Intersurgical, Wokingham, UK, dead space $=59 \mathrm{ml}$ ). All the patients with non-COVID-19-associated ARDS were ventilated using a heated humidifier.

\section{Data collection}

Day 0 was defined as the first calendar day after the onset of ARDS in the COVID-19 cohort or as the day of inclusion in Express trial in the non-COVID-19 cohort (mean time from the onset of ARDS to inclusion $=26.1 \pm 23.1 \mathrm{~h}$ in Express [19]).

Baseline characteristics (including age, body metrics, simplified acute physiologic score II (SAPS II) [21], partial pressure of arterial oxygen $\left(\mathrm{PaO}_{2}\right), \mathrm{FiO}_{2}$, partial pressure of arterial carbon dioxide $\left(\mathrm{PaCO}_{2}\right)$, set tidal volume $(\mathrm{Vt})$, measured respiratory rate, measured minute ventilation, set PEEP and plateau pressure) were collected on day 0 in the two cohorts.

The type of humidification device, HME or heated humidifier was also recorded in the COVID-19 cohort.

The following parameters were recorded at days 1,3 and 7 in the two cohorts (values measured from 6 to 12 am): $\mathrm{PaO}_{2}, \mathrm{FiO}_{2}, \mathrm{PaCO}_{2}$, set Vt, measured respiratory rate, measured minute ventilation, set PEEP and plateau pressure (measured by performing an inspiratory hold of 0.2 to $0.3 \mathrm{~s}$ ). The use of prone positioning and inhaled nitric oxide before day 28 was also recorded.

The diagnosis of thromboembolic event (including deep venous thrombosis on Doppler Ultra Sound or acute pulmonary embolism on CT pulmonary angiography) before day 28 was recorded in the COVID-19 cohort.

Mortality was assessed at day 28 in the two cohorts.

\section{Calculated parameters}

PBW was calculated using the following formula: PBW $($ in $\mathrm{kg})=50+(0.91 \times$ [height in $\mathrm{cm}-152.4])$ in men and $\mathrm{PBW}=45.5+(0.91 \times[$ height in $\mathrm{cm}-152.4])$ in women [22].

The alveolar-arterial oxygen gradient ( $\mathrm{A}-\mathrm{a} \mathrm{O}_{2}$ gradient) was estimated as follows:
A-a $\quad \mathrm{O}_{2} \quad$ gradient $=\left(\left[\left(\mathrm{PB}-\mathrm{PH}_{2} \mathrm{O}\right) \times \mathrm{FiO}_{2}\right)-\left(\mathrm{PaCO}_{2}\right.\right.$ $\left.(\mathrm{mmHg}) / \mathrm{RQ})]-\mathrm{PaO}_{2}(\mathrm{mmHg})\right)$ where $\mathrm{PB}$ is the barometric pressure, $\mathrm{PH}_{2} \mathrm{O}$ the partial pressure of water and RQ the respiratory quotient. $\mathrm{PB}, \mathrm{PH}_{2} \mathrm{O}$ and $\mathrm{RQ}$ were considered as equal to $760 \mathrm{mmHg}, 47 \mathrm{mmHg}$ and 0.8 , respectively.

Estimated $C_{\mathrm{RS}}$ was computed as tidal volume divided by the difference between plateau pressure and set PEEP.

VR was computed as minute ventilation $(\mathrm{ml} /$ $\left.\mathrm{min}) \times \mathrm{PaCO}_{2}(\mathrm{mmHg})\right] /(\mathrm{PBW}(\mathrm{kg}) \times 100 \times 37.5)[23]$.

$\mathrm{PaO}_{2} / \mathrm{FiO}_{2}, \mathrm{~A}-\mathrm{a} \mathrm{O}_{2}$ gradient, $C_{\mathrm{RS}}$ and VR were calculated at days 1,3 and 7 .

\section{Statistical analysis}

To select well-balanced subsets of patients from the COVID-19-associated ARDS cohort and non-COVID19-associated ARDS cohort, the following covariates were identified to build a propensity-score: age, SAPS II score, $\mathrm{PaO}_{2} / \mathrm{FiO}_{2}$ ratio and PEEP level on day 0 [24]. The closest controls (from the non-COVID-19-associated ARDS cohort) for COVID-19 cases were identified with the smallest average absolute distance across all the matched pairs using the "optimal" method package MatchIt [24, 25]. Only controls with pulmonary nonCOVID-19-associated ARDS were kept in the final analysis sample (see details in Additional file 1).

Results are presented as median [interquartile range] or number (\%). Baseline characteristics and ventilatory parameters at days 1, 3 and 7 were compared between the two groups using Mann-Whitney test for quantitative variables and Chi-square test for categorical variables. A Wilcoxon signed rank test was used to compare variables between day 1 and day 7. Correlations between ventilatory parameters were assessed using Spearman test. To identify variables associated with $C_{\mathrm{RS}}$ and VR at day 1 and day 7 successively, multiple linear regression models were built separately for $C_{\mathrm{RS}}$ and VR-dependent variables, including COVID-19 diagnosis, set PEEP, $\mathrm{PaO}_{2} / \mathrm{FiO}_{2}$ ratio as independent variables and additionally humidification device for VR. These independent variables were predefined based on a physiological reasoning. The mortality at day 28 was compared between the patients with VR at day 1 lower or higher than 2 in the patients with COVID-19 and in those with pulmonary non-COVID19-associated ARDS.

All tests were performed with a type I error set at 0.05 . The statistical analysis was performed using $R$ version 3.6.2 (R Core Team (2019), R: a language and environment for statistical computing, $\mathrm{R}$ Foundation for Statistical Computing, Vienna, Austria. URL https:// www.R-project.org/.) and Prism (GraphPad Software v5.0b, La Jolla, CA, USA). 


\section{Results}

Flow chart, patients characteristics and ventilatory parameters at inclusion

One hundred and thirty-five patients with COVID19-associated ARDS and 767 patients with nonCOVID-19-associated ARDS were, respectively, included. One hundred and twelve patients with COVID-19-associated ARDS could be matched with 198 patients with pulmonary non-COVID-19-associated ARDS and were enrolled in the study (Additional file 2: Fig. S1).

The main characteristics and ventilatory parameters at inclusion of the matched patients are described in Table 1.

The main characteristics and ventilatory parameters at inclusion of all the patients included in the two cohorts before matching are available in Additional file 2: Table S1.
Ventilatory parameters at day 1, day 3 and day 7 in patients with COVID-19 and non-COVID-19-associated ARDS

Ventilatory parameters changes in matched COVID19-associated ARDS and pulmonary non-COVID-19-associated ARDS at day 1, day 3 and day 7 are presented in Table 2 and Fig. 1. Prone positioning was used in 61 (54\%) and 44 (22\%) matched patients with COVID19 and non-COVID-19-associated ARDS, respectively $(p<0.001)$ and inhaled nitric oxide was used in $14(13 \%)$ and 57 (29\%) matched patients with COVID-19 and nonCOVID-19-associated ARDS, respectively ( $p=0.001)$.

$\mathrm{PaO}_{2} / \mathrm{FiO}_{2}$ ratio was not different between the two patients' groups at day 1 but became higher in the patients with non-COVID-19-associated ARDS than in those with COVID-19-associated ARDS at day 3 and day 7 (Fig. 1A). $\mathrm{PaO}_{2} / \mathrm{FiO}_{2}$ ratio was higher at day 7 than at day 1 in the patients with pulmonary nonCOVID-19-associated ARDS but not in those with COVID-19-associated ARDS. A-a $\mathrm{O}_{2}$ gradient was not different between the two patients' groups at day 1, day 3 and day 7 but became lower at day 7 compared to day

Table 1 Characteristics and ventilatory parameters at inclusion of the matched patients with COVID-19 and pulmonary non-COVID-19 ARDS

\begin{tabular}{|c|c|c|c|}
\hline & $\begin{array}{l}\text { COVID-19 patients } \\
n=112\end{array}$ & $\begin{array}{l}\text { Pulmonary non-COVID-19 ARDS patients } \\
n=198\end{array}$ & $p$ value \\
\hline Age, years & $63[51-72]$ & $60[48-71]$ & 0.196 \\
\hline SAPS $\|$ & $47[37-58]$ & 48 [37-59] & 0.562 \\
\hline Female sex, $\mathrm{n}$ & $36(32)$ & $50(25)$ & 0.193 \\
\hline $\mathrm{BMl}, \mathrm{kg} \mathrm{m}^{-2}$ & 29 [26-33] & 26 [23-29] & $<0.001$ \\
\hline \multicolumn{4}{|l|}{ ARDS severity, $n$} \\
\hline Mild & $20(18)$ & $51(26)$ & 0.112 \\
\hline Moderate & $66(59)$ & $117(59)$ & 0.978 \\
\hline Severe & $26(23)$ & $30(15)$ & 0.706 \\
\hline Tidal volume, $\mathrm{ml} \mathrm{kg}{ }^{-1}$ PBW & $6.1[5.9-6.9]$ & $6.9[6.1-8.1]$ & $<0.001$ \\
\hline Respiratory rate, cycles $\mathrm{min}^{-1}$ & $27[25-30]$ & 30 [25-35] & $<0.001$ \\
\hline Volume minute, $\mathrm{L} \mathrm{min}^{-1}$ & $10.5[9.3-11.8]$ & $11.7[10-14]$ & $<0.001$ \\
\hline $\mathrm{PaCO}_{2}, \mathrm{mmHg}$ & 38 [34-43] & $43[37-49]$ & $<0.001$ \\
\hline PEEP set, $\mathrm{cmH}_{2} \mathrm{O}$ & $12[10-14]$ & $10[9-12]$ & 0.072 \\
\hline Plateau pressure, $\mathrm{cmH}_{2} \mathrm{O}$ & 24 [20-27] & 25 [22-28] & 0.655 \\
\hline Respiratory system compliance, $\mathrm{ml} \mathrm{cmH}_{2} \mathrm{O}^{-1}$ & $35[28-43]$ & $28[23-36]$ & $<0.001$ \\
\hline $\mathrm{PaO}_{2} / \mathrm{FiO}_{2}, \mathrm{mmHg}$ & 143 [103-184] & $134[98-178]$ & 0.404 \\
\hline $\mathrm{A}-\mathrm{a} \mathrm{O}_{2}$ gradient, $\mathrm{mmHg}$ & $347[242-514]$ & $351[271-485]$ & 0.554 \\
\hline Ventilatory ratio & $1.5[1.3-2.0]$ & $2.0[1.6-2.6]$ & $<0.001$ \\
\hline \multicolumn{4}{|l|}{ Cause of lung injury, $n$} \\
\hline COVID-19 & $112(100)$ & - & - \\
\hline Pneumonia & - & $151(76)$ & - \\
\hline Aspiration & - & $47(24)$ & - \\
\hline
\end{tabular}

SAPS II, simplified acute physiology score II; $\mathrm{BMI}$, body mass index; PBW, predicted body weight; PEEP, positive end expiratory pressure; PaO ${ }_{2}$, partial pressure of arterial oxygen; $\mathrm{FiO}_{2}$, fraction of inspired oxygen; $\mathrm{A}-\mathrm{a} \mathrm{O}_{2}$ gradient, alveolar-arterial oxygen gradient; PaCO ${ }_{2}$, partial pressure of arterial carbon dioxide. Results are presented as median [interquartile range] or number (\%) 
Table 2 Ventilatory parameters in matched patients with COVID-19 $(n=112)$ and non-COVID-19 pulmonary ARDS $(n=198)$ at days 1 , 3 and 7

\begin{tabular}{|c|c|c|c|c|c|c|c|c|c|}
\hline & \multicolumn{3}{|l|}{ Day 1} & \multicolumn{3}{|l|}{ Day 3} & \multicolumn{3}{|l|}{ Day 7} \\
\hline & COVID-19 & $\begin{array}{l}\text { Non- } \\
\text { COVID-19 }\end{array}$ & $p$ value & COVID-19 & $\begin{array}{l}\text { Non- } \\
\text { COVID-19 }\end{array}$ & $p$ value & COVID-19 & $\begin{array}{l}\text { Non- } \\
\text { COVID-19 }\end{array}$ & $p$ value \\
\hline Extubated, n & $0(0)$ & $3(2)$ & 0.556 & $5(4)$ & $14(7)$ & 0.463 & $27(24)$ & $38(19)$ & 0.313 \\
\hline On PSV, n & $11(10)$ & $0(0)$ & $<0.001$ & $25(22)$ & $5(3)$ & $<0.001$ & $31(28)$ & $16(9)$ & $<0.001$ \\
\hline On $A C V, n$ & $97(87)$ & $186(93)$ & 0.062 & $75(68)$ & $162(82)$ & 0.005 & $38(34)$ & $119(60)$ & $<0.001$ \\
\hline On ECMO, n & $2(2)$ & $0(0)$ & 0.130 & $3(3)$ & $0(0)$ & 0.046 & $7(6)$ & $0(0)$ & $<0.001$ \\
\hline $\begin{array}{l}\text { Tidal volume, } \\
\mathrm{ml} \mathrm{kg} \mathrm{PBW}^{-1}\end{array}$ & 6.1 [5.9-6.8] & $6.0[6.0-6.0]$ & 0.014 & 6.1 [5.9-6.9] & $6.0[6.0-6.1]$ & 0.190 & $6.4[5.9-7.4]$ & 6.0 [6.0-6.8] & 0.572 \\
\hline $\begin{array}{l}\text { Respiratory } \\
\text { rate, } \text { min }^{-1}\end{array}$ & 27 [24-30] & $30[26-34]$ & $<0.001$ & 28 [25-33] & 29 [24-33] & 0.884 & 31 [26-35] & $26[20-32]$ & 0.007 \\
\hline $\begin{array}{l}\text { Minute Ventila- } \\
\text { tion, } \mathrm{L} \mathrm{min}^{-1}\end{array}$ & $10.9[9.3-12.6]$ & 11.9 [9.8-13.0] & 0.059 & 11.5 [10.3-14.2] & 11.6 [10.0-13.2] & 0.553 & $12.3[10.4-14.6]$ & $12.5[10.4-14.0]$ & 0.954 \\
\hline $\begin{array}{l}\text { PEEP set, } \\
\mathrm{CmH}_{2} \mathrm{O}\end{array}$ & 12 [10-14] & 12 [8-16] & 0.744 & 12 [9-14] & $10[7-16]$ & 0.489 & 14 [10-15] & $7[5-10]$ & $<0.001$ \\
\hline $\begin{array}{l}\text { Plateau pres- } \\
\text { sure, } \mathrm{CmH}_{2} \mathrm{O}\end{array}$ & 24 [21-28] & 27 [22-28] & 0.029 & 25 [21-28] & 26 [20-28] & 0.832 & 27 [23-28] & 23 [19-28] & 0.017 \\
\hline $\mathrm{FiO}_{2}$ & $0.5[0.4-0.7]$ & $0.6[0.5-0.8]$ & 0.021 & $0.5[0.4-0.6]$ & $0.5[0.3-0.7]$ & 0.426 & $0.5[0.4-0.7]$ & $0.5[0.4-0.6]$ & 0.649 \\
\hline $\mathrm{pH}$ & 7.39 [7.33-7.45] & $7.36[7.30-7.41]$ & $<0.001$ & $7.38[7.33-7.43]$ & $7.40[7.35-7.44]$ & 0.109 & $7.41[7.34-7.43]$ & $7.43[7.37-7.48]$ & 0.001 \\
\hline $\mathrm{PaCO}_{2}, \mathrm{mmHg}$ & $42[36-46]$ & 43 [39-50] & 0.030 & 44 [40-49] & 42 [37-50] & 0.163 & $48[41-55]$ & $42[36-48]$ & $<0.001$ \\
\hline
\end{tabular}

PSV, pressure support ventilation; ACV, assisted controlled ventilation; ECMO, extracorporeal membrane oxygenation; PBW, predicted body weight; PEEP, positive end-expiratory pressure; $\mathrm{FiO}_{2}$, fraction of inspired oxygen; $\mathrm{PaCO}_{2}$, partial pressure of arterial carbon dioxide. Results are presented as median [interquartile range] or number (\%)

1 only in the patients with non-COVID-19-associated ARDS (Fig. 1B).

$C_{\mathrm{RS}}$ was higher in the COVID-19 patients than in the control non-COVID-19 patients at day 1 and but not at days 3 and 7 (Fig. 1C).

VR was lower in the patients with COVID-19-associated ARDS than in the patients with non-COVID19-associated ARDS at day 1 but was not different between the two groups at days 3 and 7 (Fig. 1D). VR significantly increased from day 1 to day 7 only in patients with COVID-19-associated ARDS.

\section{Relationship between $\mathrm{PaO}_{2} / \mathrm{FiO}_{2}$ ratio and $\mathrm{C}_{\mathrm{RS}}$ or VR in patients with COVID-19 and non-COVID-19-associated ARDS}

At day $1, C_{\mathrm{RS}}$ was positively correlated with the $\mathrm{PaO}_{2} / \mathrm{FiO}_{2}$ ratio in the patients with pulmonary nonCOVID-19-associated ARDS, but not in those with COVID-19-associated ARDS (Fig. 2A). These two parameters were correlated in the two groups of patients at day 7 (Fig. 2B).

VR was negatively correlated with the $\mathrm{PaO}_{2} / \mathrm{FiO}_{2}$ ratio in the patients with COVID-19 and in those with pulmonary non-COVID-19-associated ARDS at day 1 and day 7 (Additional file 2: Fig. S2A and Fig. S2B).
Determinants of $C_{\mathrm{RS}}$ and VR from day 1 to day 7 in patients with COVID-19 and non-COVID-19-associated ARDS

\section{Changes in VR from day 1 to day 7 in patients with COVID-19-associated ARDS according to the humidification device}

Among the 112 matched patients with COVID-19-associated ARDS, 60 (54\%) were ventilated using an HME and $52(46 \%)$ were ventilated using a heated humidifier. VR was higher at days 1, 3 and 7 in the COVID-19 patients ventilated using an HME than in those ventilated using a heated humidifier (Fig. 3). In patients with COVID-19-associated ARDS, VR increased from day 1 to day 7 whatever the used humification device. Minute ventilation, $\mathrm{PaCO}_{2}, \mathrm{pH}$ and PEEP levels in the COVID19 patients ventilated using a HME and in those ventilated using a heated humidifier are presented in Additional file 2: Table S2.

VR was higher at day 1 in control non-COVID-19 patients (all ventilated using a heated humidifier) than in COVID-19 patients ventilated using a heated humidifier $(p<0.001)$. VR was not different at days 3 and 7 between COVID-19 patients ventilated using a heated humidifier and control non-COVID-19 patients ( $p=0.270$ and $p=0.746$, respectively). 
A
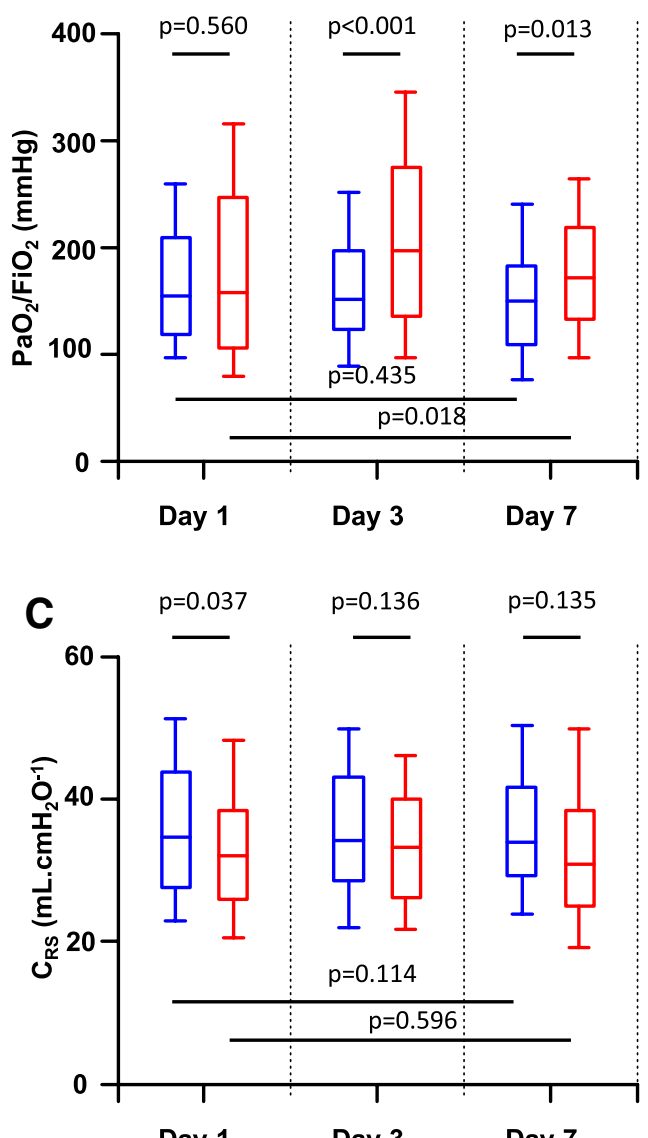

B

$\square$ COVID-19

$\square$ Non-COVID-19
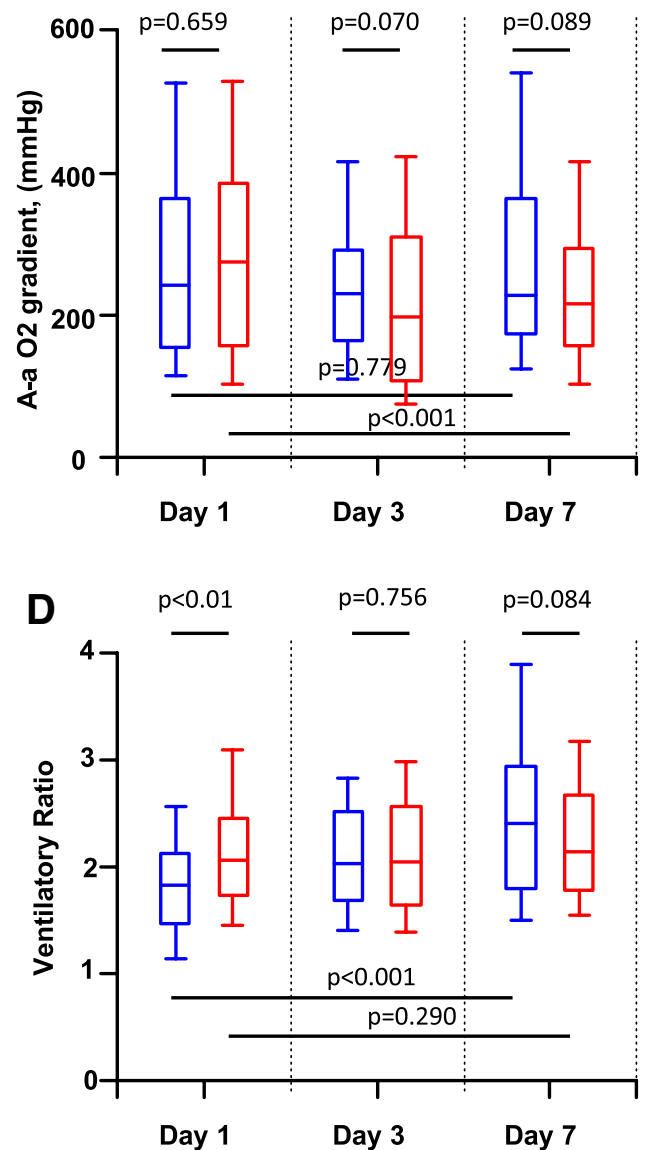

Fig. 1 Ratio of partial pressure of arterial oxygen $\left(\mathrm{PaO}_{2}\right)$ over fraction of inspired oxygen $\left(\mathrm{FiO}_{2}\right)(\mathbf{A})$, alveolar-arterial oxygen gradient $\left(\mathrm{A}\right.$-a $\mathrm{O}_{2}$ gradient) $(\mathbf{B})$, compliance of the respiratory system $\left(C_{R S}\right)(\mathbf{C})$ and ventilatory ratio $(\mathbf{D})$ in matched patients with COVID-19 and non-COVID-19 pulmonary acute respiratory distress syndrome at day 1, day 3 and day 7 . Boxplots display medians, 10th, 25th, 75th, and 90th percentiles
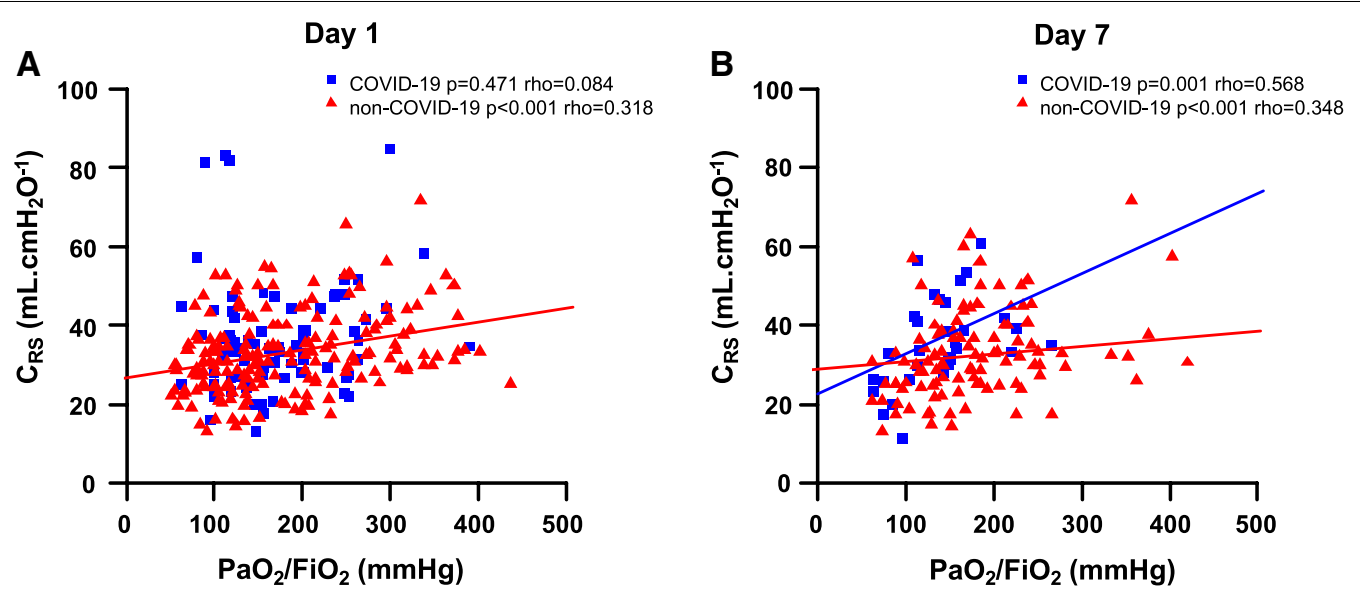

Fig. 2 Respective correlations between the ratio of partial pressure of arterial oxygen $\left(\mathrm{PaO}_{2}\right)$ over fraction of inspired oxygen $\left(\mathrm{FiO}_{2}\right)$ and the compliance of the respiratory system $\left(C_{R S}\right)$ at day $1(\mathbf{A})$ and day $7(\mathbf{B})$ in the matched patients with COVID-19 and non-COVID-19 pulmonary ARDS 


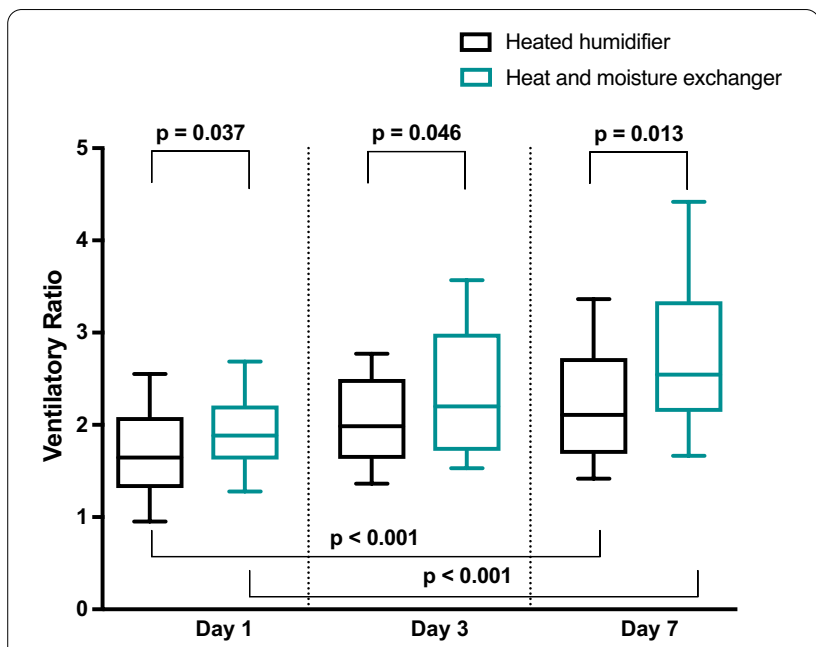

Fig. 3 Ventilatory ratio at day 1, day 3 and day 7 in patients with COVID-19-associated acute respiratory distress syndrome ventilated using a heat and moister exchanger or a heated humidifier. Boxplots display medians, 10th, 25th, 75th, and 90th percentiles

\section{Changes in VR from day 1 to day 7 in patients with COVID-19-associated ARDS according to the presence or absence of thromboembolic event}

Among the 112 matched patients with COVID-19-associated ARDS, a thromboembolic event was diagnosed in 23 patients (21\%). Among these 23 patients, a pulmonary embolism was diagnosed in 19 patients. VR was higher at days 1, 3 and 7 in the COVID-19 patients with a thromboembolic event than in those without (Additional file 2: Fig. S3). VR increased from day 1 to day 7 in the patients with COVID-19-associated ARDS with or without thromboembolic event.

\section{Multivariate analyses}

In multivariate regression analyses, after adjustment on $\mathrm{PaO}_{2} / \mathrm{FiO}_{2}$ ratio and set PEEP, $C_{\mathrm{RS}}$ was significantly higher in COVID-19 patients than in non-COVID-19 patients at day 1 , but was not significantly different at day 7, Table 3A. The $\mathrm{PaO}_{2} / \mathrm{FiO}_{2}$ ratio and the PEEP level were associated with $C_{\mathrm{RS}}$ at day 1 and day 7 .

In multivariate regression analyses, after adjustment on $\mathrm{PaO}_{2} / \mathrm{FiO}_{2}$ ratio, set PEEP and humification device, VR was significantly lower in COVID-19 patients than in non-COVID-19 patients at day 1 , but was not significantly different at day 7 , Table $3 \mathrm{~B}$. The $\mathrm{PaO}_{2} / \mathrm{FiO}_{2}$ ratio and the PEEP level were associated with VR at day 1 and day 7. The use of heated humidifier was significantly associated with lower VR than the use of HME at day 1 but not at day 7 .

\section{Outcomes}

There was no difference in overall mortality at day 28 between the patients with COVID-19-associated ARDS and the control patients with pulmonary non-COVID19-associated ARDS (25.9\% and 23.7\%, respectively, $p=0.666$ ).

There was no difference in overall mortality at day 28 between the patients with VR at day 1 higher or lower than 2 in the patients with COVID-19-associated ARDS and in those with pulmonary non-COVID-19-associated ARDS (Additional file 2: Table S3).

\section{Discussion}

The main observations of the present matched cohort study could be summarized as follows:

Table 3 Results of multivariate analyses for prediction of respiratory system compliance (A) and ventilatory ratio (B) at days 1 and 7

\begin{tabular}{|c|c|c|c|c|c|c|}
\hline & \multicolumn{3}{|c|}{$C_{\mathrm{RS}}$ at day 1} & \multicolumn{3}{|c|}{$C_{\mathrm{RS}}$ at day 7} \\
\hline & Estimate & Std. Error & $p$ value & Estimate & Std. Error & $p$ value \\
\hline \multicolumn{7}{|l|}{ (A) } \\
\hline COVID-19 versus non-COVID-19 & 4.250 & 1.512 & 0.005 & 2.460 & 3.224 & 0.447 \\
\hline PEEP & 0.726 & 0.180 & $<0.001$ & 0.671 & 0.300 & 0.027 \\
\hline \multirow[t]{3}{*}{$\mathrm{PaO}_{2} / \mathrm{FiO}_{2}$} & 0.020 & 0.009 & 0.020 & 0.057 & 0.018 & 0.002 \\
\hline & \multicolumn{3}{|c|}{ VR at day 1} & \multicolumn{3}{|c|}{ VR at day 7} \\
\hline & Estimate & Std. Error & $p$ value & Estimate & Std. Error & $p$ value \\
\hline \multicolumn{7}{|l|}{ (B) } \\
\hline COVID-19 versus non-COVID-19 & -0.691 & 0.117 & $<0.001$ & -0.135 & 0.263 & 0.608 \\
\hline PEEP & 0.022 & 0.009 & 0.021 & 0.051 & 0.015 & 0.001 \\
\hline $\mathrm{PaO}_{2} / \mathrm{FiO}_{2}$ & -0.002 & 0.001 & $<0.001$ & -0.004 & 0.001 & $<0.001$ \\
\hline Heated humidifier versus HME & -0.468 & 0.136 & 0.001 & -0.374 & 0.279 & 0.182 \\
\hline
\end{tabular}

$\mathrm{C}_{\mathrm{RS}}$, respiratory system compliance; $\mathrm{PEEP}$, positive end-expiratory pressure; $\mathrm{VR}$, ventilatory ratio; $\mathrm{PaO}_{2}$, partial pressure of arterial oxygen; FiO ${ }_{2}$, fraction of inspired oxygen; HME, heat and moisture exchanger 
1. COVID-19-associated ARDS patients exhibited significantly higher $C_{\mathrm{RS}}$ at day 1 than pulmonary nonCOVID-19-associated ARDS patients, matched on age, SAPS II, $\mathrm{PaO}_{2} / \mathrm{FiO}_{2}$ ratio and PEEP level. At day 7, $C_{\mathrm{RS}}$ did not differ between groups but hypoxemia was more profound in COVID-19 patients, suggesting the persistence of a possible dissociation between hypoxemia and respiratory mechanics.

2. Oxygenation and $C_{\mathrm{RS}}$ were positively correlated at day 1 in non-COVID-19, but not in COVID-19-associated ARDS. These parameters were positively correlated in the two groups of patients at day 7 .

3. By contrast with our expectation, COVID-19-associated ARDS patients exhibited lower VR at day 1 compared to non-COVID-19 patients. VR of COVID19-associated ARDS significantly increased during the first week of evolution and tended to be higher at day 7 in COVID-19 than in non-COVID-19 patients.

4. Multivariate analyses showed that differences in $C_{\mathrm{RS}}$ and VR observed between COVID-19 and pulmonary non-COVID-19-associated ARDS at day 1 no longer existed at day 7 after adjustment on PEEP level, $\mathrm{PaO}_{2} / \mathrm{FiO}_{2}$ ratio and humidification device.

Previously published studies assessing respiratory mechanics of COVID-19-associated ARDS showed heterogenous results [12-16]. The present study is the first to compare the evolution of respiratory mechanics in COVID-19 and non-COVID-19 pulmonary ARDS over a seven-day period. The slightly but significantly higher $C_{\mathrm{RS}}$ measured at day 1 in COVID-19 compared to nonCOVID-19 patients is consistent with previous observations $[14,16]$. Some authors suggested that a relatively high compliance associated with low $\mathrm{PaO}_{2} / \mathrm{FiO}_{2}$ ratio may characterize a phenotype subgroup of COVID19-associated ARDS patients that deserves a specific ventilatory approach [26]. On the contrary, others advocated that "this phenotype" is simply a clinical form also observed in some non-COVID-19 ARDS patients that depends on severity and evolution [27, 28]. The present observations suggest that initial differences characterizing COVID-19 ARDS do not exist anymore at day 7.

Ventilatory ratio was lower at day 1 in patients with COVID-19, but an increase over time was observed in these patients, whereas it was not observed in control non-COVID-19 patients. The results of the multivariate analysis showing no statistical difference in VR at day 7 between COVID-19 and non-COVID-19 patients do not support that this increase in VR observed in COVID19-associated ARDS could only reflect the "pulmonary vascular alteration".

The significantly higher level of set PEEP at day 7 reported in COVID-19-associated ARDS may have directly impacted VR and $C_{\mathrm{RS}}$ changes since high PEEP levels may lead to overdistension and increase alveolar dead space. This difference may be explained by several differences concerning the initial unusual clinical presentation of COVID 19-ARDS as well as the ventilation strategies since more than 10 years separate the two cohorts. As a result, physiological observations performed in the present study might reflect more differences in management strategies rather than differences in pathophysiology. Thus, the multivariate analysis showed that no difference in VR or $C_{\mathrm{RS}}$ was observed between COVID-19 and non-COVID-19 patients after adjustment on PEEP level.

Importantly, in patients with COVID-19-associated ARDS, the substantially lower VR observed in the subgroup of patients ventilated with a heated humidifier suggests that a large part of the increase in VR may be related to the additional instrumental dead space induced by the HME filter as previously described [29]. The humidification device is thus an important determinant of dead space that has not been specifically considered in previous studies reporting increased VR in COVID19 patients [7]. The impact of the increased instrumental dead space on $\mathrm{PaCO}_{2}$ depends on respiratory rate and $\mathrm{Vt}$ combinations [30]. Thus, the lower respiratory rate and slightly higher Vt might have contributed to the lower VR observed in COVID-19 patients at day 1.

The difference observed at day 1 between COVID19 and non-COVID-19 patients is consistent with the description of patients having a higher compliance for the same level of oxygenation. In addition, our observations show that the natural course of evolution after intubation tends to erase the differences in compliance but that COVID-19 patients become more hypoxemic, again suggesting a dissociation between hypoxemia and compliance. Recent data suggest that tidal volume reduction is mostly beneficial for patients with low compliance, and our data are therefore important in this context [31]. Patients' management must be individually adapted to the disease severity and the physiological measurements of driving pressure and compliance rather than the initial presentation.

Our study has several limitations. First, the number of patients included in the analysis is relatively small despite the two centers design of the study. Second, as discussed above, we cannot exclude that part of the ventilation strategies not considered in the analysis have changed between the two cohorts. We observed differences in the use of prone positioning, and inhaled nitric oxide between COVID-19 and nonCOVID-19 patients. Differences in non-invasive oxygenation strategies before intubation may also have impacted the results. And changes in sedation level and 
neuromuscular blockers use may be associated with changes in $\mathrm{CO}_{2}$ production and thus with $\mathrm{PaCO}_{2}$ and VR. Third, we limited the analysis to patients with different causes of pulmonary ARDS since it was not possible to identify patients with "pure" viral pneumonia in the non-COVID-19 cohort. Fourth, although VR has been reported in several studies and its reliability is well accepted, VR is definitively different than a direct measurement of alveolar dead space, which requires a cumbersome technique rarely used in clinical studies [6, 32]. In addition, total PEEP was not systemically monitored and set PEEP was used to calculate $C_{\mathrm{RS}}$. Furthermore, recruitment induced by PEEP was not assessed in the present study, while it has been shown to change over time [17]. Lastly, thromboembolic events were not collected in the Express study. In the COVID-19 cohort, thromboembolic events were confirmed based on pulmonary CT and/or ultrasound in patients exhibiting clinical suspicion. And despite their potential interest for the diagnosis of thromboembolic events, D-dimer values were not systematically monitored in COVID-19 patients [33].

\section{Conclusion}

Patients with COVID-19-associated ARDS exhibited at day 1 a slightly but significantly higher compliance dissociated from oxygenation and a lower VR compared to patients with non-COVID-19 pulmonary ARDS. VR significantly increased during the first week of evolution in COVID-19 but not in non-COVID-19 patients. Differences observed at day 1 were no longer existing at day 7 after adjustment on PEEP, $\mathrm{PaO}_{2} / \mathrm{FiO}_{2}$ ratio and humidification device. The present findings suggest that specific features of COVID-19 ARDS observed at day 1 disappeared during the first week of evolution due to the natural course of ARDS and the differences in ventilatory management compared to non-COVID-19 pulmonary ARDS.

\section{Abbreviations \\ A-a $\mathrm{O}_{2}$ gradient: Alveolar-arterial oxygen gradient; ARDS: Acute Respiratory Distress Syndrome; $C_{\mathrm{RS}}$ : Respiratory system compliance; $\mathrm{FiO}_{2}$ : Fraction of inspired oxygen; $\mathrm{HME}$ : Heat and moisture exchanger; $\mathrm{PaCO}_{2}$ : Partial pressure of arterial carbon dioxide; $\mathrm{PaO}_{2}$ : Partial pressure of arterial oxygen; PBW: Pre- dicted body weight; PEEP: Positive end-expiratory pressure; SAPS II: Simplified acute physiologic score II; Vt:Tidal volume; VR: Ventilatory ratio.}

\section{Supplementary Information}

The online version contains supplementary material available at https://doi. org/10.1186/s13054-021-03665-8.

Additional file 1: Case-control selection

Additional file 2: Supplementary tables and figures

\section{Acknowledgements}

The authors would like to greatly acknowledge all the medical and non-medical teams of the Angers and Strasbourg Medical ICUs.

\section{Authors' contributions}

$F B, J C R, L B$ and $A M$ designed the study. FB, AS, JCR, CD, NF, HM, BP, JH, SC, SM, $J D$ and FM conducted the study. VS performed statistical analysis. FB, AS, JCR, $C D, N F, B P, L B, A M$ and FM analyzed and interpreted the data. All authors read and approved the final manuscript.

\section{Funding}

$\mathrm{CD}$ and $\mathrm{NF}$ received a 1-year research fellowship grant from the University Hospital of Angers, France. BP received a 1-year research fellowship grant from the University Hospital of Réunion, France.

\section{Availability of data and materials}

The datasets analyzed during the current study are available from the corresponding author on reasonable request.

\section{Declarations}

\section{Ethics approval and consent to participate}

The data collection was approved by the Ethics Committees of the University Hospital of Angers (\# 2020/31) and Strasbourg (\#RNI 2020 - HUS N7815). As the data were routinely acquired during usual care, signed informed consent was not required.

\section{Consent for publication}

Not applicable.

\section{Competing interests}

FB reports personal fees from Löwenstein Medical and research support from Covidien, Getinge Group and GE Healthcare, outside this work. JCR reports part-time salary for research activities from Air Liquide Medical Systems and Vygon and grants from Creative Air Liquide, outside this work. LB reports research grants and/or research support from Medtronic Covidien, Fisher Paykel, Philips, Sentec, Air Liquide Medical Systems and GE Healthcare, outside this work. AM reports personal fees from Faron Pharmaceuticals, Air Liquid Medical Systems, Pfizer, Resmed and Draeger and grants and personal fees from Fisher and Paykel and Covidien, outside this work. The other authors have no conflict of interest to declare.

\section{Author details}

${ }^{1}$ Medical ICU, University Hospital of Angers, Vent'Lab, University of Angers, Angers, France. ${ }^{2}$ CNRS, INSERM 1083, MITOVASC, University of Angers, Angers, France. ${ }^{3}$ Medical ICU, University Hospital of Strasbourg, University of Strasbourg, Strasbourg, France. ${ }^{4}$ Oncology Data Factory and Analytics, ICO Integrated Center for Oncology, Angers, France. ${ }^{5}$ INSERM, UMR 955 Eq 13, University of Paris-Est-Créteil, Créteil, France. ${ }^{6}$ INSERM (French National Institute of Health and Medical Research), UMR 1260, Regenerative Nanomedicine (RNM), FMTS, Strasbourg, France. ${ }^{7}$ Keenan Research Centre, Li Ka Shing Knowledge Institute, St. Michael's Hospital, Toronto, Canada. ${ }^{8}$ Interdepartmental Division of Critical Care Medicine, University of Toronto, Toronto, Canada.

Received: 8 March 2021 Accepted: 4 July 2021

Published online: 15 July 2021

\section{References}

1. Grasselli G, Zangrillo A, Zanella A, Antonelli M, Cabrini L, Castelli A, et al. Baseline characteristics and outcomes of 1591 patients infected with SARS-CoV-2 admitted to ICUs of the Lombardy Region, Italy. JAMA. 2020;323:1574-81.

2. Wu C, Chen X, Cai Y, Xia J, Zhou X, Xu S, et al. Risk factors associated with acute respiratory distress syndrome and death in patients with coronavirus disease 2019 pneumonia in Wuhan, China. JAMA Intern Med. 2020;180:934-43. 
3. ARDS Definition Task Force, Ranieri VM, Rubenfeld GD, Thompson BT, Ferguson ND, Caldwell E, et al. Acute respiratory distress syndrome: the Berlin Definition. JAMA. 2012;307:2526-33.

4. Gattinoni L, Coppola S, Cressoni M, Busana M, Rossi S, Chiumello D. COVID-19 does not lead to a "typical" acute respiratory distress syndrome. Am J Respir Crit Care Med. 2020;201:1299-300.

5. Patel BV, Arachchillage DJ, Ridge CA, Bianchi P, Doyle JF, Garfield B, et al. Pulmonary angiopathy in severe COVID-19: physiologic, imaging and hematologic observations. Am J Respir Crit Care Med. 2020. https://doi. org/10.1164/rccm.202004-14120C.

6. Sinha P, Calfee CS, Beitler JR, Soni N, Ho K, Matthay MA, et al. Physiologic analysis and clinical performance of the ventilatory ratio in Acute Respiratory Distress Syndrome. Am J Respir Crit Care Med. 2019;199:333-41.

7. Liu X, Liu X, Xu Y, Xu Z, Huang Y, Chen S, et al. Ventilatory ratio in hypercapnic mechanically ventilated patients. Am J Respir Crit Care Med. 2020;201:1297-9.

8. Ackermann M, Verleden SE, Kuehnel M, Haverich A, Welte T, Laenger F, et al. Pulmonary vascular endothelialitis, thrombosis, and angiogenesis in Covid-19. N Engl J Med. 2020;383:120-8.

9. Helms J, Tacquard C, Severac F, Leonard-Lorant I, Ohana M, Delabranche $X$, et al. High risk of thrombosis in patients with severe SARS-CoV-2 infection: a multicenter prospective cohort study. Intensive Care Med. 2020;46:1089-98

10. Trigonis RA, Holt DB, Yuan R, Siddiqui AA, Craft MK, Khan BA, et al. Incidence of venous thromboembolism in critically ill coronavirus disease 2019 patients receiving prophylactic anticoagulation. Crit Care Med. 2020:48:805-8

11. Parzy G, Daviet F, Puech B, Sylvestre A, Guervilly C, Porto A, et al. Venous thromboembolism events following venovenous extracorporeal membrane oxygenation for severe acute respiratory syndrome coronavirus 2 based on CT scans. Crit Care Med. 2020:48:e971-5.

12. Haudebourg A-F, Perier F, Tuffet S, de Prost N, Razazi K, Mekontso Dessap A, et al. Respiratory mechanics of COVID-19- versus non-COVID-19-associated Acute Respiratory Distress Syndrome. Am J Respir Crit Care Med. 2020;202:287-90.

13. Ziehr DR, Alladina J, Petri CR, Maley JH, Moskowitz A, Medoff BD, et al. Respiratory pathophysiology of mechanically ventilated patients with COVID-19: a cohort study. Am J Respir Crit Care Med. 2020;201:1560-4.

14. Grieco DL, Bongiovanni F, Chen L, Menga LS, Cutuli SL, Pintaudi G, et al. Respiratory physiology of COVID-19-induced respiratory failure compared to ARDS of other etiologies. Crit Care. 2020;24:529.

15. Brault C, Zerbib Y, Kontar L, Fouquet U, Carpentier M, Metzelard M, et al. COVID-19 Versus non-COVID-19-related acute respiratory distress syndrome: differences and similarities. Am J Respir Crit Care Med. 2020;202:1301-4. https://doi.org/10.1164/rccm.202005-2025LE.

16. Grasselli G, Tonetti T, Protti A, Langer T, Girardis M, Bellani G, et al. Pathophysiology of COVID-19-associated acute respiratory distress syndrome: a multicentre prospective observational study. Lancet Respir Med. 2020;8:1201-8

17. Beloncle FM, Pavlovsky B, Desprez C, Fage N, Olivier P-Y, Asfar P, et al. Recruitability and effect of PEEP in SARS-Cov-2-associated acute respiratory distress syndrome. Ann Intensive Care. 2020;10:55.

18. Pelosi P, D'Onofrio D, Chiumello D, Paolo S, Chiara G, Capelozzi VL, et al. Pulmonary and extrapulmonary acute respiratory distress syndrome are different. Eur Respir J Suppl. 2003;42:48s-56s.
19. Mercat A, Richard JC-M, Vielle B, Jaber S, Osman D, Diehl JL, et al. Positive end-expiratory pressure setting in adults with acute lung injury and acute respiratory distress syndrome: a randomized controlled trial. JAMA. 2008;299:646-55.

20. Bernard GR, Artigas A, Brigham KL, Carlet J, Falke K, Hudson L, et al. TheAmerican-European consensus conference on ARDS. Definitions, mechanisms, relevant outcomes, and clinical trial coordination. Am J Respir Crit Care Med. 1994;149:818-24.

21. Le Gall JR, Lemeshow S, Saulnier F. A new Simplified Acute Physiology Score (SAPS II) based on a European/North American multicenter study. JAMA. 1993;270:2957-63.

22. Ventilationwith lower tidal volumes as compared with traditional tidal volumes for acutelung injury and the Acute Respiratory Distress Syndrome. N Engl J Med. 2000;342:1301-8.

23. Wexler HR, Lok P. A simple formula for adjusting arterial carbon dioxide tension. Can Anaesth Soc J. 1981:28:370-2.

24. GuXS, Rosenbaum PR. Comparison of multivariate matching methods: structures, distances, and algorithms. J Comput Graph Stat. 1993;2:405-20

25. Ho D, Imai K, King G, Stuart EA. Matchlt: nonparametric preprocessing for parametric causal inference. J Stat Softw. 2011;42:1-28.

26. Gattinoni L, Chiumello D, Caironi P, Busana M, Romitti F, Brazzi L, et al. COVID-19 pneumonia: different respiratory treatments for different phenotypes? Intensive Care Med. 2020;46:1099-102.

27. Panwar R, Madotto F, Laffey JG, Van Haren FMP. Compliance phenotypes in early ARDS before the COVID-19 pandemic. Am J Respir Crit Care Med. 2020. https://doi.org/10.1164/rccm.202005-20460C

28. Goligher EC, Ranieri VM, Slutsky AS. Is severe COVID-19 pneumonia a typical or atypical form of ARDS? And does it matter? Intensive Care Med. 2020;47:83-5

29. Morán I, Bellapart J, Vari A, Mancebo J. Heat and moisture exchangers and heated humidifiers in acute lung injury/acute respiratory distress syndrome patients. Effects on respiratory mechanics and gas exchange. Intensive Care Med. 2006;32:524-31.

30. Lellouche F, Delorme M, Brochard L. Impact of respiratory rate and dead space in the current era of lung protective mechanical ventilation. Chest. 2020;158:45-7.

31. Goligher EC, Costa ELV, Yarnell CJ, Brochard L, Stewart TE, Tomlinson $\mathrm{G}$, et al. Effect of lowering Vt on mortality in acute respiratory distress syndrome varies with respiratory system elastance. Am J Respir Crit Care Med. 2021;203:1378-85.

32. Diehl J-L, Peron N, Chocron R, Debuc B, Guerot E, Hauw-Berlemont C, et al. Respiratory mechanics and gas exchanges in the early course of COVID-19 ARDS: a hypothesis-generating study. Ann Intensive Care. 2020;10:95.

33. Sakr Y, Giovini M, Leone M, Pizzilli G, Kortgen $\mathrm{A}$, Bauer $\mathrm{M}$, et al. Pulmonary embolism in patients with coronavirus disease-2019 (COVID-19) pneumonia: a narrative review. Ann Intensive Care. 2020;10:124.

\section{Publisher's Note}

Springer Nature remains neutral with regard to jurisdictional claims in published maps and institutional affiliations.

Ready to submit your research? Choose BMC and benefit from:

- fast, convenient online submission

- thorough peer review by experienced researchers in your field

- rapid publication on acceptance

- support for research data, including large and complex data types

- gold Open Access which fosters wider collaboration and increased citations

- maximum visibility for your research: over 100M website views per year

At BMC, research is always in progress.

Learn more biomedcentral.com/submissions 